\title{
Learning Outcome After Different Combinations of Seven Learning Activities in Basic Life Support on Laypersons in Workplaces: a Cluster Randomised, Controlled Trial
}

\author{
Helene Bylow $^{1}$ (D) Thomas Karlsson ${ }^{2} \cdot$ Margret Lepp $^{3,4,5} \cdot$ Andreas Claesson $^{6} \cdot$ Jonny Lindqvist $^{7} \cdot$ Leif Svensson $^{6}$. \\ Johan Herlitz ${ }^{1,7,8}$
}

Accepted: 6 November 2020 / Published online: 18 November 2020

(C) The Author(s) 2020

\begin{abstract}
Background The goal for laypersons after training in basic life support (BLS) is to act effectively in an out-of-hospital cardiac arrest situation. However, it is still unclear whether BLS training targeting laypersons at workplaces is optimal or whether other effective learning activities are possible.

Aim The primary aim was to evaluate whether there were other modes of BLS training that improved learning outcome as compared with a control group, i.e. standard BLS training, six months after training, and secondarily directly after training.

Methods In this multi-arm trial, lay participants $(n=2623)$ from workplaces were cluster randomised into 16 different BLS interventions, of which one, instructor-led and film-based BLS training, was classified as control and standard, with which the other 15 were compared. The learning outcome was the total score for practical skills in BLS calculated using the modified Cardiff Test.

Results Four different training modes showed a significantly higher total score compared with standard (mean difference 2.32.9). The highest score was for the BLS intervention including a preparatory web-based education, instructor-led training, filmbased instructions, reflective questions and a chest compression feedback device (95\% CI for difference $0.9-5.0), 6$ months after training.

Conclusion BLS training adding several different combinations of a preparatory web-based education, reflective questions and chest compression feedback to instructor-led training and film-based instructions obtained higher modified Cardiff Test total scores 6 months after training compared with standard BLS training alone. The differences were small in magnitude and the clinical relevance of our findings needs to be further explored.

Trial Registration ClinicalTrials.gov Identifier: NCT03618888. Registered August 07, 2018 — Retrospectively registered, https:// clinicaltrials.gov/ct2/show/NCT03618888
\end{abstract}

Keywords Basic life support · Learning activities · Learning outcome · Out-of-hospital cardiac arrest · Cardiopulmonary resuscitation · Automated external defibrillation

Helene Bylow

helene.bylow@gu.se

1 Department of Molecular and Clinical Medicine, Institute of Medicine, Sahlgrenska Academy, University of Gothenburg, Gothenburg, Sweden

2 Health Metrics Unit, Institute of Medicine, Sahlgrenska Academy, University of Gothenburg, Gothenburg, Sweden

3 Institute of Health and Care Sciences, Sahlgrenska Academy, University of Gothenburg, Gothenburg, Sweden
4 Østfold University College, Halden, Norway

5 School of Nursing and Midwifery, Griffith University, Brisbane, Australia

6 Department of Medicine, Centre for Resuscitation Science, Karolinska Institute, Stockholm, Sweden

7 Centre of Registers Västra Götaland, Gothenburg, Sweden

8 Prehospen-Centre of Prehospital Research, Faculty of Caring Science, Work Life and Social Welfare, University of Borås, Borås, Sweden 


\section{Introduction}

Learning activities in basic life support (BLS) for laypersons must bridge the reality of an out-of-hospital cardiac arrest (OHCA) situation. It is urgent to alert the emergency medical service (EMS) and initiate high-quality cardiopulmonary resuscitation (CPR) and automated external defibrillation (AED) [1-5]. Medical and educational scientific guidelines in BLS are updated continuously to improve the outcome of cardiac arrest $[1-4,6,7]$.

The learning outcome for training in BLS includes sufficient practical skills and theoretical knowledge. Experiential learning might be appropriate in order to understand the process of learning BLS. According to Kolb's experiential learning theory, learning is individual and comprises four stages: (1) concrete experience, (2) reflective observation, (3) abstract conceptualisation and (4) active experimentation [8]. Different learning activities may create different conditions for learning [8].

Instructor-directed training compared with self-directed training and video-based instructions has been shown to be as good as instructions from the instructor alone [2, 9-13]. Peer learning, in which students interact with each other in order to learn, has also been shown to be effective [14]. Previous studies have reported that the quality of the chest compressions appears to be better when they are facilitated by an instructor compared with self-learning [15], with brief retraining within 6 months [16], in compression-only CPR [17] and when a feedback device for correct compressions was used [17-20]. In contrast, compressions may be too deep if a CPR feedback device is used $[19,21]$. Moreover, the consideration of mastery learning, when the participant trains until mastery level is attained and checked by assessment, and deliberate practice, when learning is achieved by focusing deliberately on change to reach the goal, is recommended [2, $4,22,23]$. In addition, learning can take the form of traditional BLS training, with all the information delivered at the same time, or it can be spaced out in the form of a low dose of training at high frequency $[2,4,24]$. Retraining for laypersons is recommended more often than once a year, as the quality decreases after 3 to 6 months [2]. Further, contextual learning with time for experience and reflection such as team training in scenarios with feedback appears to increase communication and learning in practical skills in BLS [2, 4]. Moreover, multimedia tools, such as mobile devices, video films and webbased platforms, constitute the current infrastructure and reflection on the learning process is essential $[25,26]$.

Globally, cardiovascular disease (CVD) is a major public health issue and an increased level of educated community members may increase cardiovascular health [5]. Workplaces in Sweden are subject to the Work Environment Act, which includes sufficient theoretical knowledge and practical skills in first aid and BLS for employees [27, 28].
Despite this, there is a lack of various learning activities to bridge an effective workplace-based learning to reach preparedness of an acute life-threatening situation. In addition, time for learning is needed so that the person really learns to perform the task.

There are scientific gaps in relation to educational interventions in BLS, including OHCA, CVD and the effectiveness of digital strategies $[3,4,17,26]$. Little is known about various learning activities and blended learning in BLS targeting laypersons at workplaces. In two previous studies, we compared self-learning versus instructor-led learning and a preparatory web-based education versus no web-based education [29-31]. In this study with new analysis, we intended to cover some of the residual knowledge gap on different learning activities and compared 15 different combinations of seven learning activities with a standard BLS training. The primary aim of this study was thus to evaluate whether there were other modes of BLS training that improved learning outcome as compared with a control group, i.e. standard BLS training, 6 months after training. The secondary aim was to evaluate learning outcome directly after training. The hypotheses were that the learning activities, instructor-led training, a preparatory webbased education, chest compression feedback and reflective questions can increase learning outcome when compared to standard training in BLS.

\section{Materials and Methods}

\section{Study Design}

This study was an educational, multi-factorial intervention in BLS, CPR and AED for laypersons at workplaces in Sweden in 2014 to 2016. The design was a 16-arm parallel-group, experimental, cluster randomised, controlled trial (RCT) according to Reporting of Multi-Arm Parallel-Group Randomized Trials Extension of the CONSORT 2010 Statement [32] and checklist (Supplemental file 1). The trial compared 15 different interventions in BLS with a control group which was classified as standard, i.e. instructor-led and film-based BLS training. A formal power calculation was performed in two previous publications [29-31].

\section{Randomisation}

Allocated laypersons were cluster randomised to one of 16 BLS training interventions using blocks of 25 individuals in 112 clusters calculated by the randomizer.org [33]. The generated interventions were delivered to the participants and the instructors by an independent co-ordinator at the central municipal and at the workplaces. The participants were only aware of their individual intervention. The BLS instructors were aware of the learning objective for the instructor-led 
intervention but not the study aim, trial design, randomisation or the overall interventions. According to the PROBE (Prospective Randomised Open Blinded End-Point Evaluation) design [34], the investigator (HB) was blinded to the randomisation of the participants, the training and the participants' intervention at the assessment. The trial was registered at ClinicalTrials.gov (ID: NCT03618888).

\section{Study Population}

The study population ( $n=2623$ ) was recruited from 84 workplaces in the community outside hospitals, in the south of Sweden. The criteria for inclusion were laypersons with no BLS training at all (CPR 35.5\%, AED 79.6\%) or without prior BLS training within 5 years or longer (CPR $64.5 \%$, AED $20.4 \%$ ) and 18 years of age or older. The criteria for exclusion were that potential candidates for participation were either healthcare professionals or participants who had not performed the retention test. The participants and workplaces were given both oral and written information and written informed consent was obtained from all the participants.

\section{Intervention}

The BLS algorithm was according to the 2010 European Resuscitation Council (ERC) guidelines [35, 36]. Seven additional learning activities were explored in 16 different combinations, of which one was the control group. All the interventions included both theory and practice in BLS and the participants trained on a personal mini-manikin and a paperboard AED in a kit (Mini Anne Plus kit, Laerdal Medical, Stavanger, Norway). The participants self-assessed their practical skills level for the compressions by clicking for correct hand placement and depth and a raised chest for correct ventilation on the training manikin. The learning objective, which was the same for all the participants, was to train BLS according to guidelines and the BLS algorithm with the recognition of a victim in cardiac arrest, alerting the EMS, performing CPR (30 compressions and two ventilations) and using the AED. Half the interventions were self-directed, and the other half were instructor directed. For instructions, four self-learning groups were directed by a mobile application and 12 interventions were film based. The instructor-led training included involvement in a brief two-person mini-manikin OHCA scenario. Half the interventions included a preparatory web-based interactive education on stroke, acute myocardial infarction (AMI), OHCA, CPR, AED and healthy lifestyle factors. Half the interventions included three reflective essential questions put to the participants on calling for help, hand position for chest compressions and willingness to act in a real-life OHCA situation. In four of the interventions, a device for feedback on chest compression depth placed on the manikin's chest was used. The duration of the instructor-led training was defined in the design of the study. The self-learning group could train for as long time as they wanted even if the instruction in the mobile application was $30 \mathrm{~min}$ and the instruction in the film was $60 \mathrm{~min}$. Therefore, the exact duration for the training in all the learning activities was not defined. The approximate times for the duration of each learning material are presented in Table 1. A detailed description of the interventions is presented in Supplementary file 2.

One or two instructors from the workplaces facilitated the instructor-led interventions. In total, 16 instructors, accredited by the Swedish resuscitation council, with about 10 years of experience were updated to $2010 \mathrm{ERC}$ guidelines.

\section{Data Collection and Assessment}

Data were collected directly after the training and 6 months after the training through individual questionnaires (Supplementary file 3) and an assessment of BLS skills in a practical test. The test was performed on a Resusci Anne fullbody manikin and a HeartStart 1 AED trainer (Laerdal Medical AS, Stavanger, Norway). To compare learning outcomes, BLS skills were measured by the PC Skill Reporting system software V.2.4 (Laerdal Medical, Stavanger, Norway) and the total score (19-70 points) was calculated from the variables in the BLS algorithm using the validated modified version of the Cardiff Test of basic life support and external defibrillation (Cardiff Test, Supplementary file 4). The test was conducted as an OHCA scenario in a private setting in a converted motor home stationed outside the workplace. After permission from the participant, a stopwatch and the software automatically measured the variables and a mounted Sony HD video camera filmed the scenario. The test lasted for about 5 $\min$. Three minutes was required for the participant to be able to recognise the OHCA victim, shout for help, call 112, ask for an AED and perform CPR, while about 2 min was required to use the AED. At 3 min from the start of the scenario, the assessor placed the AED next to the manikin. The equipment was calibrated automatically and checked manually every day, and, in the event of technical problems, an identical training manikin and AED was prepared.

\section{Outcome}

The primary outcome was the total score for practical BLS skills calculated with the modified Cardiff Test, 6 months after training, while the secondary outcome was the total score calculated directly after training.

\section{Statistical Analysis}

The data on participant characteristics are presented as the median or percentages. 


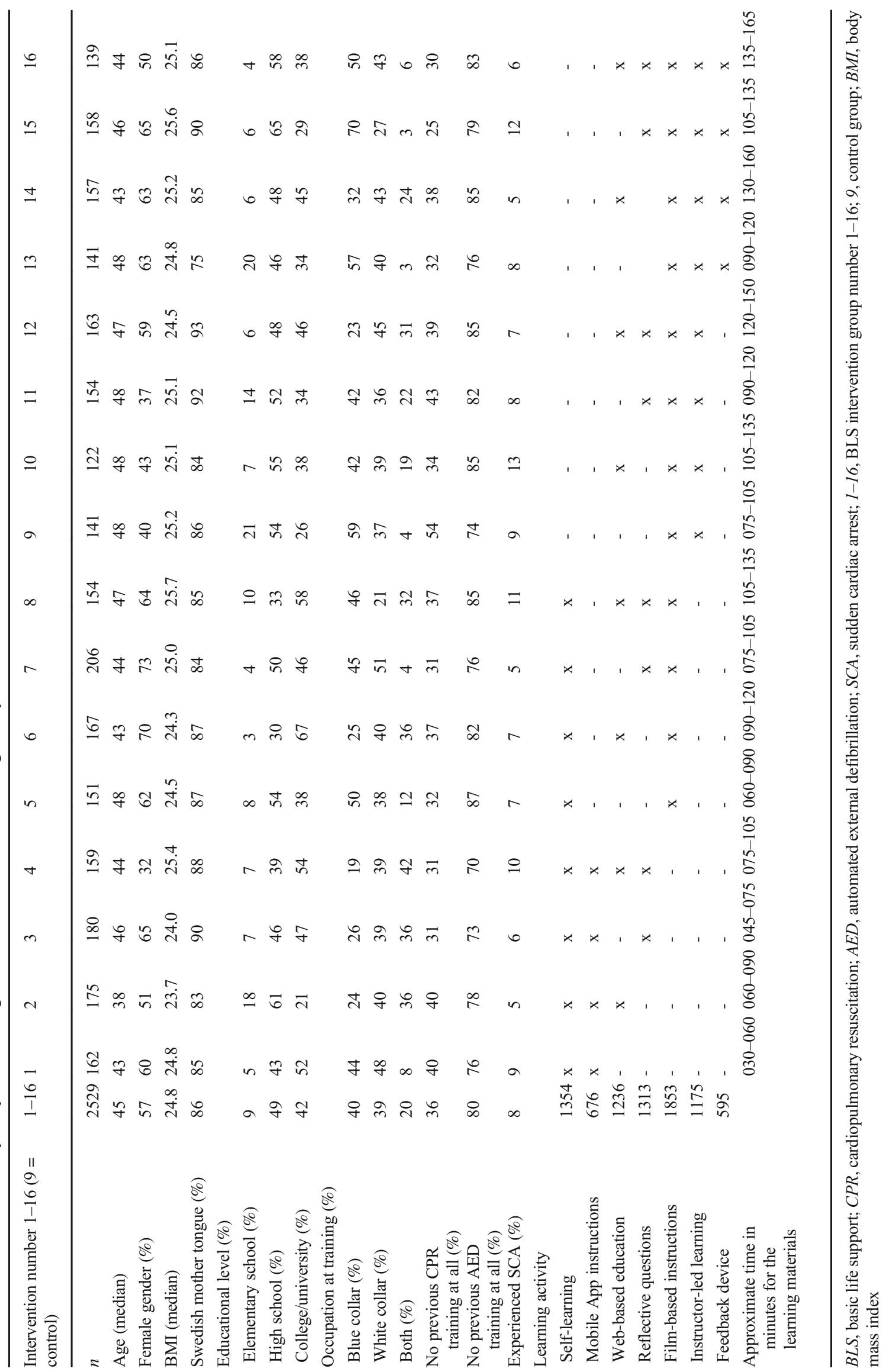


Mixed linear regression models were applied for comparisons of the modified Cardiff Test total score to account for a potential cluster effect in the intervention groups. Due to imbalances between the groups in terms of participant characteristics, comparisons were made with adjustments for the possible confounding influence of age, gender, body mass index, mother tongue, educational level and occupation at training and previous CPR training and training on AED use.

Least square means with corresponding standard errors are presented for each intervention group, together with $95 \%$ confidence intervals and $p$ values for the difference from group 9 (standard), adjusted for multiple comparisons using Dunnett's method. Standardised effect size (Cohen's $d$ ) is also given for each comparison with group 9 regarding Cardiff Test total score.

All tests are two-sided and $p$ values below 0.05 were considered statistically significant. SAS for Windows version 9.4 was used for all the performed analyses.

\section{Ethics}

The Regional Ethical Review Board in Gothenburg approved the ethical application on 23 March 2014 (2014/134-14).

\section{Results}

This multi-arm parallel cluster RCT enrolled 2623 laypersons recruited from workplaces in a BLS educational project from 2014 to 2016, of which 2529 were eligible for analysis either at 6 months $(n=2480)$ or directly $(n=2425)$ after training. The characteristics of the participants are presented in Table 1. The participants were randomised to one of 16 adult BLS training interventions with different additional learning activities (Fig. 1). For physical and mental reasons and because of a shortage of time and stress, 94 participants were lost to followup directly after training and 49 between the tests. For the primary outcome, a total score for practical skills calculated with the modified Cardiff Test 6 months after training, 2480 individuals were analysed. For the secondary outcome, 2425 individuals were analysed as 104 individual tests were incomplete for analysis at the test directly after training but were complete for analysis at the test 6 months after training. The mean total score for the modified Cardiff Test (19-70 points) including all 16 groups was $59.1(84 \%)$ directly after training and $58.4(83 \%) 6$ months after training.

\section{Primary Outcome}

Due to imbalances between the intervention groups in terms of participant characteristics, comparisons were adjusted for these imbalances.
For the primary outcome, i.e. BLS practical skills 6 months after training, four of the interventions obtained a significantly higher modified Cardiff Test total score compared with the control group (number 9), i.e. BLS instructor-led practical training with film-based instructions (Table 2). The standardised effect size is also presented for differences from the control group 9 in Table 2 . The four interventions are as follows:

1. BLS training intervention number 16 , including all additional learning activities, i.e. a preparatory web-based education, instructor-led training, film-based instructions, three reflective essential questions and use of a chest compression feedback device

2. BLS training intervention number 11, with instructor-led training including film-based instructions and three reflective questions

3. BLS training intervention number 10 , including a preparatory web-based education, instructor-led training and film-based instructions

4. BLS training intervention number 14 , including a preparatory web-based education, instructor-led training, filmbased instructions and compression feedback.

A description of individual items in the Cardiff Test score (Table 3) and separate variables (Table 4) for these four interventions and the control group are given as unadjusted comparisons. Although all but one of the other eleven training interventions obtained a higher total score than the control group, none of these differences was statistically significant.

Separate variables, variables for quality of practical skills for cardiopulmonary resuscitation (CPR) and automated external defibrillation (AED), 6 months after training in basic life support (BLS)

Data was collected from the Resusci Anne Manikin connected to the PC Skill Reporting system (Laerdal Medical, Stavanger, Norway) and from direct observation. All results are crude, i.e. not adjusted for clustering or imbalances in participants' characteristics. All available data was used

\section{Secondary Outcome}

For secondary outcome, i.e. BLS skills directly after training, intervention numbers 16, 12 and 14, all including a preparatory web-based interactive education, instructor-led training and film-based instructions, obtained a significantly higher modified Cardiff Test total score compared with the control group, when adjustment was made for imbalances in participants' characteristics (Table 5).

Theoretical knowledge on first action if stroke or AMI and OHCA, i.e. call 112, general symptoms of stroke and AMI and healthy lifestyle factors, self-assessed theoretical 
Fig. 1 CONSORT flow diagram. 15 different basic life support (BLS) training interventions were compared in a multi-arm parallel design with one control group, number 9 (no. 9), i.e. a standard instructor-led and film-based BLS training. The experimental interventions from the multi-arm cluster randomised controlled trial, numbers $1-8$ and $10-16$, were additional to practical BLS training and consisted of seven learning activities in different combinations. The total number of participants for each intervention, 1 16 , is shown in parentheses

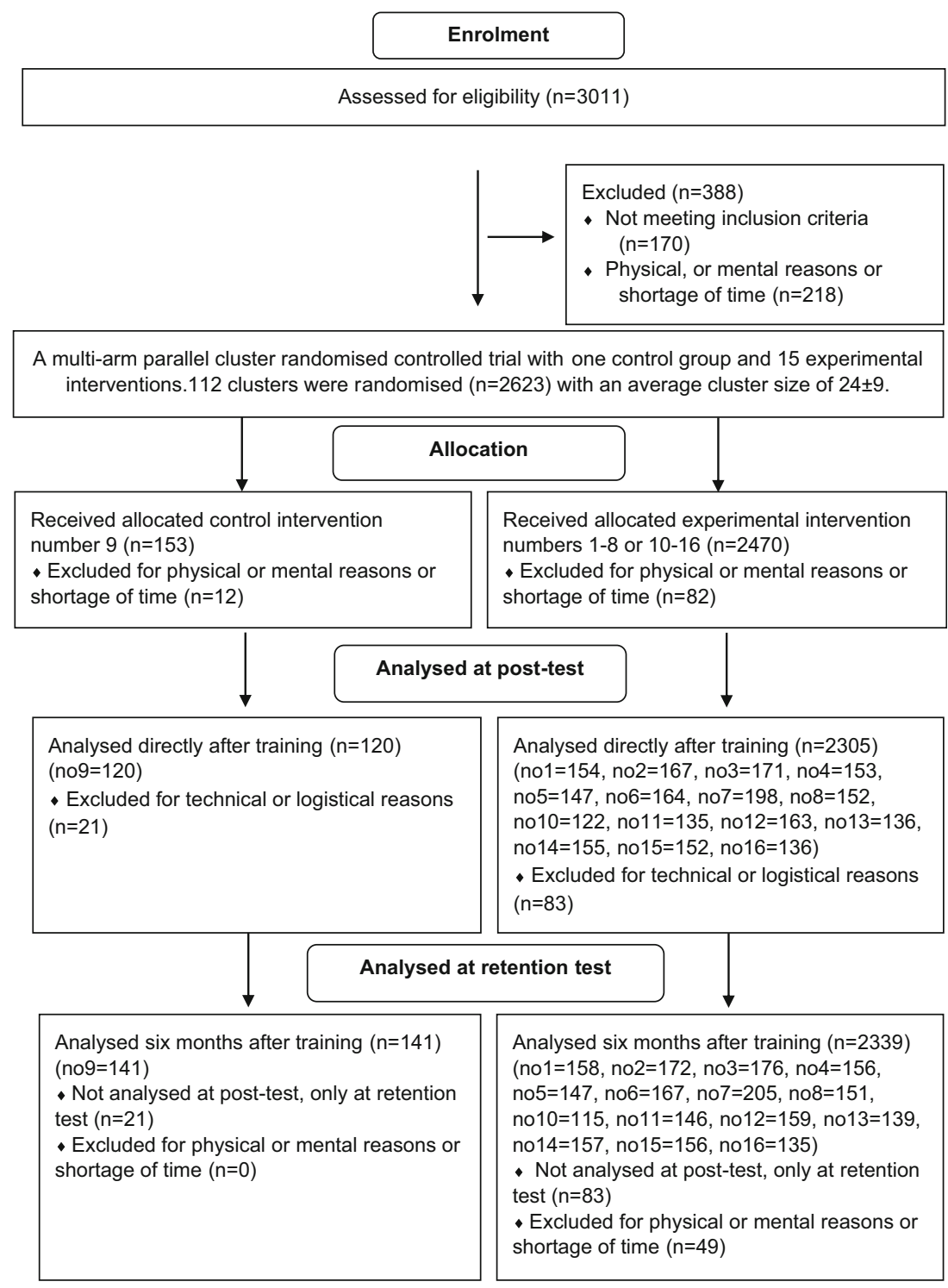

knowledge and practical skills, confidence and willingness to act in a real-life OHCA situation, directly and 6 months after training are described in Supplementary file 5, Table 6a and $6 \mathrm{~b}$ respectively.

\section{Discussion}

The main results in this cluster RCT showed that a preparatory interactive web-based education on CVD, a feedback device on the quality of compressions and reflective essential questions, in addition to instructor-led and film-based training, appear to provide potential benefits for practical skills in BLS when compared with the standard, 6 months after training. However, the clinical impact and the way these three additional learning activities could be combined in an optimal way have been investigated but it is still unclear and further studies are required to explore this issue.

Yet, all three learning activities have previously been reported to be beneficial for learning. Firstly, E-learning has been reported to be as good as lectures and teaching before training [2, 37-39], and a web-based education prior to practical training in BLS to laypersons showed a slightly higher total score compared to BLS training without the web-based education [31]. Secondly, CPR feedback devices have resulted in improved quality in CPR and are recommended in training $[2,6]$. Thirdly, some form of reflection is proven to increase effective learning in an educational setting [8, 40].

Moreover, the results in this study indicate that an instructor who facilitated the interventions appeared to be favourable for learning. This is in line with a systematic review by Chen et al., who presented interventions that improved high-quality CPR by laypersons and the result showed that an instructor or 
Table 2 Total score practical skills in BLS, 6 months after training

\begin{tabular}{|c|c|c|c|c|c|c|c|c|}
\hline & \multicolumn{4}{|l|}{ Unadjusted } & \multicolumn{4}{|l|}{ Adjusted $^{\#}$} \\
\hline & lsmeans \pm stderr* & $95 \% \mathrm{CI}^{* *}$ & $p^{* *}$ & Effect size ${ }^{* * *}$, & lsmeans \pm stderr* & $95 \% \mathrm{CI}^{* *}$ & $p^{* *}$ & Effect size ${ }^{6 * *}$ \\
\hline \multicolumn{9}{|c|}{ Intervention } \\
\hline 1 & $57.0 \pm 0.53$ & -1.4 to 3.0 & 0.95 & 0.16 & $55.7 \pm 0.51$ & -2.1 to 1.9 & 1.00 & -0.03 \\
\hline 2 & $58.0 \pm 0.54$ & -0.5 to 4.0 & 0.20 & 0.24 & $56.9 \pm 0.51$ & -1.1 to 3.0 & 0.77 & 0.19 \\
\hline 3 & $58.3 \pm 0.54$ & -0.1 to 4.3 & 0.08 & 0.39 & $57.1 \pm 0.51$ & -0.8 to 3.3 & 0.50 & 0.23 \\
\hline 4 & $58.9 \pm 0.55$ & 0.5 to 5.0 & 0.008 & 0.53 & $57.6 \pm 0.52$ & -0.3 to 3.8 & 0.15 & 0.34 \\
\hline 5 & $57.5 \pm 0.53$ & -0.9 to 3.5 & 0.52 & 0.25 & $56.8 \pm 0.52$ & -1.1 to 2.9 & 0.85 & 0.17 \\
\hline 6 & $57.8 \pm 0.53$ & -0.6 to 3.8 & 0.29 & 0.31 & $56.4 \pm 0.51$ & -1.5 to 2.6 & 1.00 & 0.11 \\
\hline 7 & $58.2 \pm 0.49$ & -0.1 to 4.2 & 0.07 & 0.38 & $57.1 \pm 0.47$ & -0.7 to 3.2 & 0.40 & 0.24 \\
\hline 8 & $58.8 \pm 0.56$ & 0.4 to 4.9 & 0.01 & 0.50 & $57.9 \pm 0.54$ & -0.1 to 4.1 & 0.07 & 0.38 \\
\hline 10 & $59.0 \pm 0.62$ & 0.4 to 5.2 & 0.01 & 0.51 & $58.1 \pm 0.58$ & 0.1 to 4.4 & 0.03 & 0.42 \\
\hline 11 & $59.0 \pm 0.57$ & 0.5 to 5.1 & 0.008 & 0.51 & $58.5 \pm 0.55$ & 0.5 to 4.7 & 0.006 & 0.48 \\
\hline 12 & $58.4 \pm 0.53$ & -0.0 to 4.4 & 0.05 & 0.40 & $57.4 \pm 0.51$ & -0.5 to 3.5 & 0.24 & 0.28 \\
\hline 13 & $58.1 \pm 0.54$ & -0.3 to 4.2 & 0.14 & 0.34 & $57.6 \pm 0.52$ & -0.3 to 3.7 & 0.16 & 0.31 \\
\hline 14 & $59.2 \pm 0.54$ & 0.7 to 5.2 & 0.003 & 0.58 & $58.1 \pm 0.52$ & 0.2 to 4.3 & 0.02 & 0.44 \\
\hline 15 & $58.5 \pm 0.49$ & 0.2 to 4.5 & 0.03 & 0.44 & $57.5 \pm 0.50$ & -0.3 to 3.6 & 0.17 & 0.31 \\
\hline 16 & $60.0 \pm 0.55$ & 1.5 to 6.0 & $<0.0001$ & 0.72 & $58.8 \pm 0.54$ & 0.9 to 5.0 & 0.001 & 0.56 \\
\hline 9 control & $56.2 \pm 0.57$ & - & - & - & $55.9 \pm 0.54$ & - & - & - \\
\hline
\end{tabular}

\# Adjusted for age, mother tongue, educational level, previous cardiopulmonary resuscitation (CPR) training, gender, body mass index (BMI), occupation and previous automated external defibrillation (AED) use training. *Least square means with corresponding standard errors. CI, confidence interval; $p, p$ values below 0.05 were considered statistically significant. **For comparison with the control group. '**'Standardised effect size (Cohen's $d$ ) for comparison with control group 9 (all interventions included)

dispatcher was engaged in most of the studies which improved efficacy [17], even if self-instruction is recommended as an alternative $[2,4]$. The instructor-led training in this study offered some communication with both the instructor and the other participants. For example, in the short scenario with the small manikin at the end of the training, the participants collaborated in pairs in a brief OHCA scenario and communication may be a positive factor for learning. Experience, reflection, understanding and hands-on training may all increase learning, according to Kolb [8], may be extended by peer learning and may come closer to experiential learning $[4,8]$. Reflection on essential questions was included in half the interventions and was discussed in pairs and some peer learning may have occurred, but we are unable to confirm this. The self-learning participants reflected on their own and missed the social collaboration in the group. Reflection individually has been criticised in educational settings for the lack of sociocultural awareness and opportunity for sense-making [41]. In contrast, one study has shown non-inferiority compared with instructor-led BLS training [42] and there are opportunities for self-directed learning if they can be combined with, for example, workplace collaboration and collaborative technological platforms [43].

Furthermore, compression-only CPR, real-time feedback and mobile devices with CPR instructions are factors which appear to improve efficacy [17]. Moreover, eight of the interventions were self-directed and none of them was in favour of the control group. A mobile application gave the CPR instructions for learning in four of the interventions, and even if mobile devices may delay the early start of CPR [17], this is an easy way to learn by yourself. On the other hand, the instruction in the mobile application was only $30 \mathrm{~min}$ and much shorter than that in the other interventions but we did not estimate how long time the participants actually trained the BLS tasks.

In addition to the main result, two of the learning activities, numbers 16 and 14, resulted in improvement both directly after training and 6 months after training. Six months can be regarded as long-term retention as practical skills deteriorate after 3 to 6 months $[2,6]$, but, for a workplace organisation with laypersons, it may be difficult to organise retraining every 6 months. In an RCT in 2015, Nishiyama et al. showed that a 15 -min simple chest compression-only BLS retraining 6 months after training resulted in retained efficacy in calling the EMS and chest compression skills up to 1 year [16] and this may be appropriate to use in a workplace environment.

In this study and according to the national guidelines in BLS, the instructor gave verbal feedback and helped the participants visually to achieve the learning objective and the participants self-assessed their practical skills with the 
Table 3 Cardiff Test, 6 months after intervention. Control group 9 versus interventions 10, 11, 14 and 16

\begin{tabular}{|c|c|c|c|c|c|}
\hline & $\begin{array}{l}\text { Control } \\
9\end{array}$ & $\begin{array}{l}\text { Intervention } \\
10\end{array}$ & $\begin{array}{l}\text { Intervention } \\
11\end{array}$ & $\begin{array}{l}\text { Intervention } \\
14\end{array}$ & $\begin{array}{l}\text { Intervention } \\
16\end{array}$ \\
\hline Individual items & $(n=141)$ & $(n=115)$ & $(n=146)$ & $(n=157)$ & $(n=135)$ \\
\hline \multicolumn{6}{|l|}{ Checks responsiveness - by talking } \\
\hline 2 p. Yes & 95.7 & 97.4 & 95.2 & 98.7 & 94.1 \\
\hline 1 p. No & 4.3 & 2.6 & 4.8 & 1.3 & 5.9 \\
\hline \multicolumn{6}{|l|}{ Checks responsiveness - by shaking } \\
\hline 3 p. Yes & 93.6 & 97.4 & 93.8 & 98.7 & 93.3 \\
\hline 2 p. No & 5.0 & 2.6 & 5.5 & 1.3 & 6.7 \\
\hline $1 \mathrm{p}$. Potentially dangerous & 1.4 & 0 & 0.7 & 0 & 0 \\
\hline \multicolumn{6}{|c|}{ Opens airway - by head tilt and chin lift } \\
\hline $5 \mathrm{p}$. Perfect as instructed & 24.8 & 43.5 & 41.8 & 42.0 & 40.0 \\
\hline 4 p. Acceptable & 9.9 & 6.1 & 11.0 & 8.3 & 9.6 \\
\hline 3 p. Attempted other & 2.8 & 0.9 & 2.1 & 0.6 & 0 \\
\hline 2 p. Attempted visible but fails & 14.9 & 17.4 & 15.8 & 29.9 & 24.4 \\
\hline 1 p. No & 47.5 & 32.2 & 29.5 & 19.1 & 25.9 \\
\hline \multicolumn{6}{|c|}{ Checks breathing - by look, listen and feel } \\
\hline 2 p. Yes & 75.2 & 80.0 & 85.6 & 87.3 & 87.4 \\
\hline 1 p. No & 24.8 & 20.0 & 14.4 & 12.7 & 12.6 \\
\hline \multicolumn{6}{|l|}{ Calls 112 or shouts for call to 112} \\
\hline 2 p. Yes & 90.1 & 88.7 & 95.9 & 98.7 & 97.8 \\
\hline \multirow{2}{*}{\multicolumn{6}{|c|}{ Asks for AED }} \\
\hline & & & & & \\
\hline 2 p. Yes & 77.3 & 89.6 & 87.0 & 84.1 & 92.6 \\
\hline 1 p. No & 22.7 & 10.4 & 13.0 & 15.9 & 7.4 \\
\hline \multicolumn{6}{|c|}{ Starts CPR—compression/ventilations ratio } \\
\hline 4 p. $30: 2(28-32: 2)$ & 63.1 & 77.4 & 74.7 & 86.0 & 79.3 \\
\hline 3 p. Another ratio & 35.5 & 11.7 & 25.3 & 14.0 & 20.0 \\
\hline 2 p. Compressions only & 1.4 & 0.9 & 0 & 0 & 0.7 \\
\hline $1 \mathrm{p}$. Ventilations only & 0 & 0 & 0 & 0 & 0 \\
\hline \multicolumn{6}{|l|}{ Hand placement compressions } \\
\hline 4 p. Correct & 18.4 & 29.6 & 46.6 & 13.4 & 22.2 \\
\hline 3 p. Other wrong & 39.7 & 41.7 & 36.3 & 44.6 & 52.6 \\
\hline 2 p. Too low & 41.8 & 28.7 & 17.1 & 42.0 & 25.2 \\
\hline 1 p. Not attempted & 0 & 0 & 0 & 0 & 0 \\
\hline \multicolumn{6}{|l|}{ Average compression depth } \\
\hline 6 p. $50-59 \mathrm{~mm}$ & 59.6 & 60.0 & 62.3 & 60.5 & 63.7 \\
\hline $5 \mathrm{p} . \geq 60 \mathrm{~mm}$ & 12.8 & 13.9 & 6.8 & 23.6 & 18.5 \\
\hline 4 p. $35-49 \mathrm{~mm}$ & 24.8 & 23.5 & 28.8 & 14.6 & 15.6 \\
\hline 2 p. $<35 \mathrm{~mm}$ & 2.8 & 2.6 & 2.1 & 1.3 & 2.2 \\
\hline $1 \mathrm{p}$. Not attempted & 0 & 0 & 0 & 0 & 0 \\
\hline \multicolumn{6}{|l|}{ Average compression rate } \\
\hline 6 p. $100-120$ & 36.2 & 35.7 & 45.2 & 47.1 & 46.7 \\
\hline 5 p. $121-140$ & 7.1 & 13.9 & 14.4 & 13.4 & 18.5 \\
\hline 4 p. $80-99$ & 33.3 & 34.8 & 23.3 & 26.1 & 21.5 \\
\hline 3 p. $>140$ & 0.7 & 1.7 & 1.4 & 1.3 & 0.7 \\
\hline 2 p. $<80$ & 22.7 & 13.9 & 15.8 & 12.1 & 12.6 \\
\hline $1 \mathrm{p}$. Not attempted & 0 & 0 & 0 & 0 & 0 \\
\hline Total compressions counted & & & & & \\
\hline 6 p. $140-190$ & 56.0 & 62.6 & 64.4 & 50.3 & 59.3 \\
\hline 5 p. $>190$ & 16.3 & 13.0 & 11.6 & 22.3 & 18.5 \\
\hline 4 p. $121-139$ & 12.1 & 9.6 & 8.2 & 10.2 & 10.4 \\
\hline 3 p. $81-120$ & 12.1 & 10.4 & 13.0 & 15.3 & 10.4 \\
\hline 2 p. $\leq 80$ & 3.5 & 4.3 & 2.7 & 1.9 & 1.5 \\
\hline 1 p. Not attempted & 0 & 0 & 0 & 0 & 0 \\
\hline Average ventilation volume & & & & & \\
\hline 5 p. $500-600 \mathrm{ml}$ & 7.8 & 5.2 & 15.1 & 11.5 & 17.0 \\
\hline 4 p. $1-499 \mathrm{ml}$ & 14.2 & 8.7 & 13.7 & 7.6 & 9.6 \\
\hline 3 p. $>600 \mathrm{ml}$ & 55.3 & 79.1 & 63.0 & 70.7 & 63.7 \\
\hline 2 p. $0 \mathrm{ml}$ & 21.3 & 6.1 & 8.2 & 10.2 & 8.9 \\
\hline 1 p. Not attempted & 1.4 & 0.9 & 0 & 0 & 0.7 \\
\hline Total ventilations counted & & & & & \\
\hline 5 p. $8-12$ & 43.3 & 62.6 & 60.3 & 60.5 & 60.0 \\
\hline 4 p. $1-7$ & 20.6 & 20.0 & 18.5 & 16.6 & 18.5 \\
\hline 3 p. $>12$ & 13.5 & 10.4 & 13.0 & 12.7 & 11.9 \\
\hline 2 p. 0 & 21.3 & 6.1 & 8.2 & 10.2 & 8.9 \\
\hline 1 p. Not attempted & 1.4 & 0.9 & 0 & 0 & 0.7 \\
\hline Total hands-off time & & & & & \\
\hline 4 p. $\leq 60 \mathrm{~s}$ & 4.3 & 3.5 & 4.1 & 7.6 & 4.4 \\
\hline 3 p. $61-90 \mathrm{~s}$ & 61.0 & 61.7 & 58.2 & 68.2 & 64.4 \\
\hline 2 p. $91-135 \mathrm{~s}$ & 32.6 & 32.2 & 35.6 & 24.7 & 30.4 \\
\hline 1 p. $>135 \mathrm{~s}$ & 2.1 & 2.6 & 2.1 & 0.6 & 0.7 \\
\hline Switches on AED & & & & & \\
\hline 2 p. Yes & 100 & 100 & 100 & 99.4 & 99.3 \\
\hline
\end{tabular}


Table 3 (continued)

\begin{tabular}{|c|c|c|c|c|c|}
\hline & $\begin{array}{l}\text { Control } \\
9\end{array}$ & $\begin{array}{l}\text { Intervention } \\
10\end{array}$ & $\begin{array}{l}\text { Intervention } \\
11\end{array}$ & $\begin{array}{l}\text { Intervention } \\
14\end{array}$ & $\begin{array}{l}\text { Intervention } \\
16\end{array}$ \\
\hline 1 p. No & 0 & 0 & 0 & 0.6 & 0.7 \\
\hline \multicolumn{6}{|l|}{ Attaches electrode pads } \\
\hline 6 p. Both pads completely in areas & 71.6 & 95.7 & 85.6 & 90.4 & 97.0 \\
\hline $5 \mathrm{p}$. One in area, one crossing border of area & 12.1 & 1.7 & 5.5 & 2.5 & 0.7 \\
\hline $4 \mathrm{p}$. One in area, one outside area & 10.6 & 1.7 & 3.4 & 3.8 & 0.7 \\
\hline $3 \mathrm{p}$. Both crossing border of area & 2.8 & 0.9 & 2.1 & 0 & 0.7 \\
\hline 2 p. Both outside areas & 2.8 & 0 & 3.4 & 2.5 & 0 \\
\hline $1 \mathrm{p}$. Not attached or not plugged into AED & 0 & 0 & 0 & 0.6 & 0.7 \\
\hline \multicolumn{6}{|l|}{$\begin{array}{l}\text { Checks safety, ensures nobody in } \\
\text { contact with manikin }\end{array}$} \\
\hline 2 p. Yes & 42.6 & 65.2 & 64.4 & 53.5 & 65.2 \\
\hline 1 p. No & 57.4 & 34.8 & 35.6 & 46.5 & 34.8 \\
\hline \multicolumn{6}{|l|}{ Delivers shock as directed by AED } \\
\hline 2 p. Yes & 100 & 99.1 & 100 & 99.4 & 99.3 \\
\hline 1 p. No & 0 & 0.9 & 0 & 0.6 & 0.7 \\
\hline \multicolumn{6}{|l|}{ Resumes CPR immediately after shock } \\
\hline 2 p. Yes & 87.2 & 91.3 & 89.7 & 89.2 & 88.9 \\
\hline 1 p. No & 12.8 & 8.7 & 10.3 & 10.8 & 11.1 \\
\hline
\end{tabular}

Cardiff Test, Cardiff Test of basic life support (BLS) and automated external defibrillation (AED); CPR, cardiopulmonary resuscitation. Data was collected from the Resusci Anne Manikin connected to the PC Skill Reporting system (Laerdal Medical, Stavanger, Norway) and from direct observation. All results are crude proportions (\%), i.e. not adjusted for clustering or imbalances in participants' characteristics. All available data were used

manikin. Self-assessment is possible in both instructordirected and self-directed training, but, if the assessment of the participants was performed in communication with the instructor and using technological feedback, we might have

Table 4 Separate variables, 6 months after intervention. Control group 9 versus interventions 10, 11, 14 and 16

\begin{tabular}{|c|c|c|c|c|c|}
\hline Variables & $\begin{array}{l}\text { Control } \\
9\end{array}$ & $\begin{array}{l}\text { Intervention } \\
10\end{array}$ & $\begin{array}{l}\text { Intervention } \\
11\end{array}$ & $\begin{array}{l}\text { Intervention } \\
14\end{array}$ & $\begin{array}{l}\text { Intervention } \\
16\end{array}$ \\
\hline Correct compressions $(\%)$ & $N=141$ & $N=115$ & $N=146$ & $N=157$ & $N=135$ \\
\hline Median & 29 & 48 & 49 & 48 & 63 \\
\hline 25th, 75th percentile & 2,74 & 4,84 & 18,85 & 8,79 & 14,92 \\
\hline Compressions with insufficient depth $(\%)$ & $N=141$ & $N=115$ & $N=146$ & $N=157$ & $N=135$ \\
\hline Median & 5 & 6 & 13 & 3 & 2 \\
\hline 25th, 75th percentile & 1,47 & 1,38 & 2,51 & 1,21 & 1,23 \\
\hline Compressions with incorrect hand-position (\%) & $N=141$ & $N=115$ & $N=146$ & $N=157$ & $N=135$ \\
\hline Median & 42 & 23 & 3 & 11 & 18 \\
\hline 25th, 75th percentile & 6,84 & 0,65 & 0,49 & 0,41 & 0,69 \\
\hline Compressions with incomplete release $(\%)$ & $N=141$ & $N=115$ & $N=146$ & $N=157$ & $N=135$ \\
\hline Median & 0 & 0 & 0 & 0 & 0 \\
\hline 25th, 75th percentile & 0,1 & 0,1 & 0,0 & 0,0 & 0,0 \\
\hline$>0(\%)$ & 26.2 & 30.4 & 24.0 & 24.8 & 21.5 \\
\hline Average compression depth (mm) & $N=141$ & $N=115$ & $N=146$ & $N=157$ & $N=135$ \\
\hline Median & 54 & 55 & 54 & 57 & 57 \\
\hline 25th, 75th percentile & 47,59 & 48,58 & 48,58 & 53,59 & 53,59 \\
\hline Average compression rate (per minute) & $N=141$ & $N=115$ & $N=146$ & $N=157$ & $N=135$ \\
\hline Median & 96 & 100 & 103 & 105 & 109 \\
\hline 25th, 75th percentile & 81,109 & 86,115 & 86,113 & 91,116 & 89,117 \\
\hline Correct ventilations (\%) & $N=141$ & $N=115$ & $N=146$ & $N=157$ & $N=135$ \\
\hline Median & 1 & 1 & 1 & 1 & 0 \\
\hline 25th, 75th percentile & 0,3 & 0,2 & 0,3 & 0,3 & 0,3 \\
\hline$>0(\%)$ & 53.2 & 53.9 & 63.0 & 63.1 & 50.4 \\
\hline Average ventilation volume (ml) & $N=141$ & $N=115$ & $N=146$ & $N=157$ & $N=135$ \\
\hline Median & 662 & 900 & 731 & 795 & 820 \\
\hline 25th, 75th percentile & 365,1000 & 651,1271 & 522,1070 & 547,1073 & 546,1226 \\
\hline Time to start of CPR (seconds) & $N=141$ & $N=115$ & $N=146$ & $N=157$ & $N=135$ \\
\hline Median & 27 & 28 & 29 & 25 & 29 \\
\hline 25 th, 75 th percentile & 19,35 & 23,38 & 22,36 & 19,34 & 20,35 \\
\hline Time to 1st shock (seconds) & $N=141$ & $N=115$ & $N=145$ & $N=156$ & $N=134$ \\
\hline Median & 74 & 67 & 71 & 66 & 66 \\
\hline 25 th, 75 th percentile & 64,86 & 59,78 & 59,84 & 57,78 & 58,76 \\
\hline
\end{tabular}


Table 5 Total score practical skills in BLS, directly after training

\begin{tabular}{|c|c|c|c|c|c|c|c|c|}
\hline & \multicolumn{4}{|l|}{ Unadjusted } & \multicolumn{4}{|l|}{ Adjusted $^{\#}$} \\
\hline & lsmeans \pm stderr* & $95 \% \mathrm{CI}^{* *}$ & $p^{* *}$ & Effect size ${ }^{6 * *}$ & lsmeans \pm stderr* & $95 \% \mathrm{CI}^{* *}$ & $p^{* *}$ & Effect size ${ }^{\prime * *}$, \\
\hline \multicolumn{9}{|c|}{ Intervention } \\
\hline 1 & $56.8 \pm 0.57$ & -3.9 to 0.9 & 0.49 & -0.27 & $56.0 \pm 0.55$ & -4.2 to 0.3 & 0.12 & -0.35 \\
\hline 2 & $57.5 \pm 0.59$ & -3.2 to 1.7 & 0.99 & -0.15 & $56.6 \pm 0.56$ & -3.7 to 0.9 & 0.47 & -0.28 \\
\hline 3 & $58.3 \pm 0.59$ & -2.5 to 2.5 & 1.00 & -0.00 & $57.4 \pm 0.56$ & -2.9 to 1.7 & 1.00 & -0.12 \\
\hline 4 & $58.5 \pm 0.59$ & -2.2 to 2.7 & 1.00 & 0.05 & $57.4 \pm 0.56$ & -2.9 to 1.7 & 1.00 & -0.13 \\
\hline 5 & $57.3 \pm 0.56$ & -3.4 to 1.4 & 0.88 & -0.21 & $56.7 \pm 0.55$ & -3.5 to 0.9 & 0.57 & -0.26 \\
\hline 6 & $58.5 \pm 0.58$ & -2.2 to 2.7 & 1.00 & 0.05 & $57.5 \pm 0.56$ & -2.8 to 1.8 & 1.00 & -0.10 \\
\hline 7 & $59.3 \pm 0.54$ & -1.4 to 3.3 & 0.90 & 0.21 & $58.5 \pm 0.53$ & -1.7 to 2.7 & 1.00 & 0.11 \\
\hline 8 & $58.5 \pm 0.60$ & -2.2 to 2.8 & 1.00 & 0.05 & $57.9 \pm 0.58$ & -2.4 to 2.3 & 1.00 & -0.01 \\
\hline 10 & $60.8 \pm 0.67$ & -0.2 to 5.1 & 0.08 & 0.56 & $60.0 \pm 0.63$ & -0.4 to 4.4 & 0.17 & 0.45 \\
\hline 11 & $59.8 \pm 0.61$ & -1.0 to 4.0 & 0.54 & 0.32 & $59.2 \pm 0.59$ & -1.1 to 3.6 & 0.66 & 0.27 \\
\hline 12 & $61.4 \pm 0.56$ & 0.7 to 5.5 & 0.005 & 0.74 & $60.5 \pm 0.54$ & 0.3 to 4.8 & 0.02 & 0.61 \\
\hline 13 & $59.4 \pm 0.58$ & -1.3 to 3.6 & 0.81 & 0.25 & $59.1 \pm 0.56$ & -1.2 to 3.3 & 0.78 & 0.24 \\
\hline 14 & $61.3 \pm 0.59$ & 0.6 to 5.5 & 0.007 & 0.68 & $60.5 \pm 0.57$ & 0.2 to 4.8 & 0.02 & 0.56 \\
\hline 15 & $60.0 \pm 0.52$ & -0.6 to 4.1 & 0.26 & 0.40 & $59.3 \pm 0.53$ & -0.9 to 3.5 & 0.51 & 0.30 \\
\hline 16 & $61.6 \pm 0.58$ & 0.9 to 5.8 & 0.002 & 0.78 & $60.8 \pm 0.57$ & 0.5 to 5.1 & 0.008 & 0.65 \\
\hline 9 control & $58.3 \pm 0.64$ & & - & - & $58.0 \pm 0.61$ & - & - & - \\
\hline
\end{tabular}

\# Adjusted for age, mother tongue, educational level, previous cardiopulmonary resuscitation (CPR) training, gender, body mass index (BMI), occupation and previous automated external defibrillation (AED) use training. *Least square means with corresponding standard errors. CI, confidence interval; $p, p$ values below 0.05 were considered statistically significant. **For comparison with the control group. '**'Standardised effect size (Cohen's $d$ ) for comparison with control group 9 (all interventions included)

another result. Assessment is recommended for long-term retention with mastery learning $[2,6]$. Unpredictably, directly after training, the control group, i.e. the standard group, showed a poorer result than half the interventions but without any significant difference. Learning activities without formal assessment related to the learning goal might be a weakness for learning in BLS, especially without objective and technological support [20, 44-46]. The small training manikin and the intervention itself might therefore be a weakness for the learning outcome.

Additionally, when comparing interventions numbers 10, 11, 14 and 16 with the control group 9, several individual items in the Cardiff Test and separate variables obtained higher scores.

Consequently, the preparatory interactive web-based education in addition to the instructor-led and film-based training was involved when improvement compared with standard was found at primary outcome 6 months after training. Adding theoretical knowledge on CVD as stroke, AMI and OHCA, and BLS, CPR and AED and healthy lifestyle factors may provide motivation for learning practical skills, but this is unclear. For further implementation, the web-based education could also include some synchronous brief practical selfretraining with a simple manikin, with feedback and encouragement to collaborate at the workplace and be spaced over the year. This might increase the level of re-qualified potential bystanders, as well as being easy to update, and it may reduce the financial costs and organisational affordances [11]. The educational framework at workplaces includes different types of learners and therefore needs various effective blended and spaced learning activities to enable improved learning in BLS, but we did not account for that in the study. This may be the subject of a further study.

With this third study, we conclude that the learning activities of a preparatory interactive web-based education on stroke, AMI, OHCA, CPR, AED and healthy lifestyle factors, an instructor present, film-based instructions, reflective questions and chest compressions feedback may have benefits for learning in BLS compared with instructor-led and film-based instructions alone.

\section{Strengths and Limitations}

The cluster randomised design targeted at a study population at workplaces was a strength as was the large sample size. Limitations include, in spite of the randomisation design, imbalances between the intervention groups regarding baseline characteristics. In addition, since we have no exact data on the actual time spent on each intervention, we could not adjust for 
this factor, which is a limitation. Thus, we cannot exclude the possibility that some of the differences that were found between groups may have been explained by a different duration of the training. The duration of the self-learning training was not exactly defined and that is a limitation of the study design. Furthermore, it might be argued whether the statistically significant differences are of clinical relevance since the effect size was small to moderate.

\section{Conclusion}

BLS practical training, adding different combinations of a preparatory web-based interactive education, reflective questions and chest compression feedback to instructor-led training and film-based instructions, obtained higher modified Cardiff Test total scores 6 months after training compared with instructor-led and film-based BLS training alone. The differences were small in magnitude and the clinical relevance of our findings needs to be further explored.

Supplementary Information The online version contains supplementary material available at https://doi.org/10.1007/s40670-020-01160-3.

Acknowledgements Open access funding provided by University of Gothenburg. We would like to acknowledge the participants, the workplaces, the instructors and the coordinators for participating in this study. We also want to acknowledge the interdisciplinary working group for the support with the web-based education, the Swedish national campaign, the Swedish Heart-Lung Foundation and the Swedish Resuscitation Council for the videos on stroke and OHCA. Special thanks also for the linguistic support and the quick reply.

Authors' Contributions All co-authors JH, TK, ML, AC, JL, LS and HB have contributed to the methodology, analysed the results and critically revised and have read and approved the final manuscript. HB was the main contributor to writing the manuscript. $\mathrm{JH}$ was the main supervisor. JH, LS, TK, JL and HB contributed to the conceptualisation. TK performed the formal statistical analysis.

Funding The study was funded by the Swedish Heart-Lung Foundation (20130629), the Foundation for Cardiopulmonary Resuscitation in Sweden, the Swedish Resuscitation Council and the Swedish state under the agreement between the Swedish government and the County Council (the ALF agreement, ALFGBG 716901), all without any involvement in the study.

Data Availability All data generated and analysed during this study are included in this published article and its supplementary information files.

\section{Compliance with Ethical Standards}

Competing Interests The authors declare that they have no competing interests.

Ethics Approval and Consent to Participate The Regional Ethical Review Board in Gothenburg, Sweden, approved the ethical application on 23 March 2014 (2014/134-14). Written informed consent was obtained from all the participants.

Consent for Publication Not applicable

Abbreviations AED, automated external defibrillation; AMI, acute myocardial infarction; BLS, basic life support; CI, confidence interval; CPR, cardiopulmonary resuscitation; CVD, cardiovascular disease; EMS, emergency medical service; ERC, European Resuscitation Council; OHCA, out-of-hospital cardiac arrest; PROBE, Prospective Randomised Open Blinded End-Point Evaluation; RCT, randomised, controlled trial; SCA, sudden cardiac arrest; SRC, Swedish Resuscitation Council

Open Access This article is licensed under a Creative Commons Attribution 4.0 International License, which permits use, sharing, adaptation, distribution and reproduction in any medium or format, as long as you give appropriate credit to the original author(s) and the source, provide a link to the Creative Commons licence, and indicate if changes were made. The images or other third party material in this article are included in the article's Creative Commons licence, unless indicated otherwise in a credit line to the material. If material is not included in the article's Creative Commons licence and your intended use is not permitted by statutory regulation or exceeds the permitted use, you will need to obtain permission directly from the copyright holder. To view a copy of this licence, visit http://creativecommons.org/licenses/by/4.0/.

\section{References}

1. Perkins GD, Handley AJ, Koster RW, Castrén M, Smyth MA, Olasveengen T, et al. European Resuscitation Council Guidelines for Resuscitation 2015: Section 2. Adult basic life support and automated external defibrillation. Resuscitation. 2015;95:81-99.

2. Greif R, Lockey AS, Conaghan P, Lippert A, De Vries W, Monsieurs KG. European Resuscitation Council Guidelines for Resuscitation 2015: Section 10. Education and implementation of resuscitation: Section 10. Education and implementation of resuscitation. Resuscitation. 2015;95:288-301.

3. Kleinman EM, Perkins DG, Bhanji EF, Billi EJ, Bray WJ, Callaway CC, et al. ILCOR Scientific Knowledge Gaps and Clinical Research Priorities for Cardiopulmonary Resuscitation and Emergency Cardiovascular Care: A Consensus Statement. Circulation. 2018;137:e802-e19.

4. Cheng MA, Nadkarni BV, Mancini AM, Hunt HE, Sinz ME, Merchant PR, et al. Resuscitation Education Science: Educational Strategies to Improve Outcomes From Cardiac Arrest: A Scientific Statement From the American Heart Association. Circulation. 2018;138:e82-e122.

5. Benjamin EJ, Muntner P, Alonso A, Bittencourt MS, Callaway CW, Carson AP, et al. Heart Disease and Stroke Statistics-2019 Update: A Report From the American Heart Association. Circulation. 2019:Cir0000000000000659.

6. Bhanji F, Donoghue AJ, Wolff MS, Flores GE, Halamek LP, Berman JM, et al. Part 14: Education: 2015 American Heart Association Guidelines Update for Cardiopulmonary Resuscitation and Emergency Cardiovascular Care. Circulation. 2015;132:S561-73.

7. Nolan JP, Maconochie I, Soar J, Olasveengen TM, Greif R, Wyckoff MH, et al. Executive Summary: 2020 International Consensus on Cardiopulmonary Resuscitation and Emergency Cardiovascular Care Science With Treatment Recommendations. Circulation. 2020;142:S2-S27. 
8. Kolb DA. Experiential learning: Experience as the Source of Learning and Development: Prentice Hall: New Jersey 2010; 1984.

9. Todd KH, Braslow A, Brennan RT, Lowery DW, Cox RJ, Lipscomb LE, et al. Randomized, Controlled Trial of Video SelfInstruction Versus Traditional CPR Training.(Clinical report). Ann Emerg Med. 1998;31:364.

10. Einspruch EL, Lynch B, Aufderheide TP, Nichol G, Becker L. Retention of CPR skills learned in a traditional AHA Heartsaver course versus 30-min video self-training: A controlled randomized study. Resuscitation. 2007;74:476-86.

11. Mancini ME, Cazzell M, Kardong-Edgren S, Cason CL. Improving workplace safety training using a self-directed CPR-AED learning program. AAOHN J. 2009;57:159-67 quiz 68-9.

12. Chung CH, Siu AY, Po LL, Lam CY, Wong PC. Comparing the effectiveness of video self-instruction versus traditional classroom instruction targeted at cardiopulmonary resuscitation skills for laypersons: a prospective randomised controlled trial. Hong Kong Med J. 2010;16:165-70.

13. Nielsen AM, Isbye DL, Lippert F, Rasmussen LS. Distributing personal resuscitation manikins in an untrained population: how well are basic life support skills acquired? Emerg Med J. 2012;29: 587-91.

14. Cuijpers PJ, Bookelman G, Kicken W, de Vries W, Gorgels AP. Medical students and physical education students as CPR instructors: an appropriate solution to the CPR-instructor shortage in secondary schools? Neth Hear J. 2016;24:456-61.

15. Monsieurs K, Regge M, Schelfout S, D'Hondt F, Mpotos N, Valcke M, et al. Efficacy of a self-learning station for basic life support refresher training in a hospital: A randomized controlled trial. Eur J Emerg Med. 2011;19:214-9.

16. Nishiyama C, Iwami T, Murakami Y, Kitamura T, Okamoto $\mathrm{Y}$, Marukawa S, et al. Effectiveness of simplified 15-min refresher BLS training program: a randomized controlled trial. Resuscitation. 2015;90:56-60.

17. Chen KY, Ko YC, Hsieh MJ, Chiang WC, Ma MH. Interventions to improve the quality of bystander cardiopulmonary resuscitation: A systematic review. PLoS One. 2019;14:e0211792.

18. Kramer-Johansen J, Myklebust H, Wik L, Fellows B, Svensson L, Sørebø H, et al. Quality of out-of-hospital cardiopulmonary resuscitation with real time automated feedback: A prospective interventional study. Resuscitation. 2006;71:283-92.

19. Yeung J, Meeks R, Edelson D, Gao F, Soar J, Perkins GD. The use of CPR feedback/prompt devices during training and CPR performance: A systematic review. Resuscitation. 2009;80:743-51.

20. Brennan EE, McGraw RC, Brooks SC. Accuracy of instructor assessment of chest compression quality during simulated resuscitation. Cjem. 2016;18:276-82.

21. Perkins GD, Kocierz L, Smith SCL, McCulloch RA, Davies RP. Compression feedback devices over estimate chest compression depth when performed on a bed. Resuscitation. 2009;80:79-82.

22. McGaghie WC. Mastery learning: it is time for medical education to join the 21st century. Acad Med. 2015;90:1438-41.

23. Gonzalez L, Kardong-Edgren S. Deliberate Practice for Mastery Learning in Nursing. Clin Simul Nurs. 2017;13:10-4.

24. Patocka C, Cheng A, Sibbald M, Duff JP, Lai A, Lee-Nobbee P, et al. A randomized education trial of spaced versus massed instruction to improve acquisition and retention of paediatric resuscitation skills in emergency medical service (EMS) providers. Resuscitation. 2019;141:73-80.

25. Säljö R. Digital tools and challenges to institutional traditions of learning: technologies, social memory and the performative nature of learning. J Comput Assist Learn. 2010;26:53-64.

26. Rumsfeld JS, Brooks SC, Aufderheide TP, Leary M, Bradley SM, Nkonde-Price C, et al. Use of Mobile Devices, Social Media, and Crowdsourcing as Digital Strategies to Improve Emergency
Cardiovascular Care: A Scientific Statement From the American Heart Association. Circulation. 2016;134:e87-e108.

27. Swedish Work Environment Authority. The Work Environment Act, 1977:1160. 2020. https://www.av.se/en/work-environmentwork-and-inspections/acts-and-regulations-about-workenvironment/the-work-environment-act/about-the-workenvironment-act/. Accessed 1 Jan 2019.

28. The Swedish Work Environment Authority. First aid and crisis support. 1999. https://www.av.se/globalassets/filer/publikationer/ foreskrifter/engelska/first-aid-and-crisis-support-provisionsafs 1999-7.pdf?_t_id=1B2M2Y8AsgTpgAmY7PhCfg\%3D\% 3D\&_t_q=\&_t_tags=language $\% 3 \mathrm{~A} \% 2 \mathrm{Csiteid} \% 3 \mathrm{Ae} 309 \mathrm{af0f}-$ 0167-4bd4-b12b-961c55393fb9\%2Clanguage\%3Asv\& t ip=192. 168.252.43\& t hit.id=AV Web Models Media GenericMedia/ 45e5ac33-6db5-4fda-b06d-1b0751ca39b3\&_t_hit.pos $=151 \%$. Accessed 1 Jan 2019.

29. Bylow H, Karlsson T, Claesson A, Lepp M, Lindqvist J, Herlitz J. Selflearning training versus instructor-led training for basic life support: A cluster randomised trial. Resuscitation. 2019;139:122-32.

30. Bylow H, Karlsson T, Claesson A, Lepp M, Lindqvist J, Herlitz J. Supplementary dataset to self-learning training compared with instructor-led training in basic life support. Data Brief. 2019:104064. https://doi.org/10.1016/j.dib.2019.104064.

31. Bylow H, Karlsson T, Lepp M, Claesson A, Lindqvist J, Herlitz J. Effectiveness of web-based education in addition to basic life support learning activities: A cluster randomised controlled trial. PLoS One. 2019;14:e219341.

32. Juszczak E, Altman DG, Hopewell S, Schulz K. Reporting of Multi-Arm Parallel-Group Randomized Trials: Extension of the CONSORT 2010 Statement. JAMA. 2019;321:1610-20.

33. Social Psychology Network. Research randomizer. 2014. https:// www.randomizer.org/. Accessed 1 Jan 2014.

34. Hansson L, Hedner T, Dahlof B. Prospective randomized open blinded end-point (PROBE) study. A novel design for intervention trials. Prospective Randomized Open Blinded End-Point. Blood Press. 1992;1:113-9.

35. Koster RW, Baubin MA, Bossaert LL, Caballero A, Cassan P, Castrén M, et al. European Resuscitation Council Guidelines for Resuscitation 2010 Section 2. Adult basic life support and use of automated external defibrillators. Resuscitation. 2010;81:1277-92.

36. Soar J, Monsieurs K, Ballance J, Barelli A, Biarent D, Greif R, et al. European Resuscitation Council Guidelines for Resuscitation 2010 Section 9. Principles of education in resuscitation. Notfall Rettungsmed. 2010;13:723-36.

37. Perkins GD, Fullerton JN, Davis-Gomez N, Davies RP, Baldock C, Stevens $\mathrm{H}$, et al. The effect of pre-course e-learning prior to advanced life support training: a randomised controlled trial. Resuscitation. 2010;81:877-81.

38. Thorne CJ, Lockey AS, Bullock I, Hampshire S, Begum-Ali S, Perkins GD. E-learning in advanced life support-an evaluation by the Resuscitation Council (UK). Resuscitation. 2015;90:79-84.

39. Thorne CJ, Lockey AS, Kimani PK, Bullock I, Hampshire S, BegumAli S, et al. e-Learning in Advanced Life Support-What factors influence assessment outcome? Resuscitation. 2017;114:83-91.

40. Säljö R. Learning, Theories of Learning, and Units of Analysis in Research. Educ Psychol. 2009;44:202-8.

41. McArdle K, Coutts N. Taking teachers' continuous professional development (CPD) beyond reflection: adding shared sensemaking and collaborative engagement for professional renewal. Stud Contin Educ. 2010;32:201-15.

42. Pedersen TH, Kasper N, Roman H, Egloff M, Marx D, Abegglen S, et al. Self-learning basic life support: A randomised controlled trial on learning conditions. Resuscitation. 2018;126:147-53.

43. Hillman T, Säljö R. Learning, knowing and opportunities for participation: technologies and communicative practices. Learn Media Technol. 2016;41:306-9. 
44. Kromann CB, Jensen ML, Ringsted C. The effect of testing on skills learning. Med Educ. 2009;43:21-7.

45. Kromann C, Bohnstedt C, Jensen M, Ringsted C. The testing effect on skills learning might last 6 months. Adv Health Sci Educ. 2010;15:395-401.
46. Nagafuchi K, Hifumi T, Nishimoto N, Kondo Y, Yoshikawa K, Iwami $\mathrm{T}$, et al. Chest Compression Depth and Rate - Effect on Instructor Visual Assessment of Chest Compression Quality. Circ J. 2019;83:418-23.

Publisher's Note Springer Nature remains neutral with regard to jurisdictional claims in published maps and institutional affiliations. 